\title{
ANÁLISE DA PRODUÇÃO DE FRASES NO CICLO DE ALFABETIZAÇÃO
}

\section{ANALYSIS OF PHRASE PRODUCTION IN THE LITERACY CYCLE}

\author{
ARCENIO, Cláudia Rodrigues do Carmo ${ }^{1}$
}

\begin{abstract}
RESUMO
Este artigo visa relatar uma experiência que buscou analisar as tradicionais propostas de produção de frases no ciclo de alfabetização, procurando gerir alternativas à luz de duas vertentes para a prática educativa. Uma das vertentes refere-se à gramática internalizada que cada falante possui de sua língua materna e a outra se relaciona com a proposta do letramento de forma a facilitar aprendizagens quanto à apropriação da leitura e da escrita. A partir das discussões sobre a prática pedagógica ambientadas no contexto do Pacto Nacional pela Alfabetização na Idade Certa (PNAIC) em meio às formações presenciais realizadas no município de Nova Iguaçu, Baixada Fluminense do Rio de Janeiro, buscamos analisar e gerir alternativas quanto às propostas de atividades de construção de frases durante o ciclo de alfabetização. Para tanto, analisamos as atividades realizadas por alunos de quatro escolas do município evidenciando as incoerências teórico-metodológicas presentes tanto na proposição das atividades quanto na avaliação das frases produzidas pelos educandos.
\end{abstract}

PaLAVRas CHAVe: Alfabetização; Letramento; Língua Materna; Ensino.

\section{ABSTRACT}

This article reports an experience that sought to analyze the traditional proposals of phrase production in the literacy cycle, trying to manage alternatives in the light of two aspects for the educational practice. One of the strands refers to the internalized grammar that each speaker possesses of his mother tongue and the other is related to the proposal of the literacy in order to facilitate learning about the appropriation of reading and writing. Based on the discussions about pedagogical practice set in the context of the National Pact for Literacy in the Right Age (PNAIC) during the presentations held in the municipality of Nova Iguaçu, Baixada Fluminense, Rio de Janeiro, we seek to analyze and manage alternatives to the proposed activities of sentence construction during the literacy cycle. In order to do so, we analyze the activities carried out by students from four schools in the municipality, showing the theoretical and methodological inconsistencies present both in the proposition of the activities and in the evaluation of the sentences produced by the students.

KEYWORDS: teach reading and writing; Literacy; Native language; Teaching.

\footnotetext{
${ }^{1}$ Universidade Federal Rural do Rio de Janeiro (UFRRJ). Seropédica, RJ, Brasil. Prefeitura da Cidade de Nova Iguaçu, Nova Iguaçu, RJ, Brasil. e-mail: claurodriguesmd@gmail.com
} 
DOI: $10.12957 /$ e-mosaicos.2020.45091

\section{RESUMEN}

Este artículo reporta una experiencia que buscaba analizar las propuestas tradicionales para la producción de frases en el ciclo de alfabetización, buscando gestionar alternativas de dos vías para la práctica educativa. Una de las vertientes se refiere a la gramática internalizada que cada hablante posee de su lengua materna y la otra se relaciona con la propuesta del letramento para facilitar aprendizajes en cuanto a la apropiación de la lectura y la escritura. A partir de las discusiones sobre la práctica pedagógica ambientadas en el contexto del Pacto Nacional por la Alfabetización en la Edad Cierta (PNAIC) durante las formaciones presenciales realizadas en el municipio de Nova Iguaçu, Baixada Fluminense de Río de Janeiro, buscamos analizar y gestionar alternativas en cuanto a las propuestas de actividades de construcción de frases durante el ciclo de alfabetización. Para ello, analizamos las actividades realizadas por alumnos de cuatro escuelas del municipio evidenciando las incoherencias teóricometodológicas presentes tanto en la proposición de las actividades como en la evaluación de las frases producidas por los educandos.

PALABRAS CLAVE: Alfabetización; Letramento; Lengua Materna; Enseñanza

\section{INTRODUÇÃO}

Os apontamentos apresentados neste texto surgem das inquietações manifestadas por educadoras da rede Municipal de Nova Iguaçu Baixada Fluminense do Rio de Janeiro, configuradas no ambiente de formação continuada proporcionado pelo Pacto Nacional pela Alfabetização na Idade Certa² (PNAIC), do qual atualmente sou formadora.

Característica marcante do desenvolvimento do programa em nosso município, realizado no segundo semestre de 2017, foram os encontros quinzenais com as professoras atuantes no ciclo de alfabetização da rede. Os encontros formativos centravam-se na leitura e estudo dos materiais fornecidos pelo programa e a promoção de discussões e análise de práticas efetivas em sala de aula. As turmas possuíam entre 20 a 25 professoras e foram organizadas por etapas do ciclo de alfabetização, estando sob minha orientação professoras regentes ${ }^{3}$ de turmas do $2^{0}$ ano do Ensino Fundamental, oriundas de diversas escolas rurais e urbanas da localidade.

Os alunos ${ }^{4}$ a que nos referimos, neste artigo, frequentam as aulas no período da manhã, são falantes nativos de língua portuguesa e estão predominantemente silábico-alfabéticos e alfabéticos em suas hipóteses de escrita ${ }^{5}$. Devido à organização

\footnotetext{
${ }^{2}$ Para conhecer mais sobre o Pacto Nacional pela Alfabetização na Idade Certa acesse os sites do programa disponíveis em: pacto.mec.gov.br, pnaicufrj.com

${ }^{3} \mathrm{Em}$ meu grupo de formação continuada não havia professores, somente professoras.

${ }^{4}$ Os nomes dos alunos citados no artigo são fictícios.

5 Para compreender melhor sobre as hipóteses de escrita recomendamos as leituras dos livros Psicogênese da língua escrita de Emília Ferreiro e Ana Teberosky; tradução Diana Myriam Lichtenstein, Liana Di Marco, Mário Corso. Porto Alegre: Artmed, 1999, e da coleção Didática de Alfabetização de Esther Pillar Grossi. Rio de Janeiro: Paz e Terra: 1990. Em Psicogênese da língua escrita, Emília Ferreiro considera que o processo de aquisição da leitura e da escrita passa por quatro hipóteses distintas: présilábica, silábica, silábico-alfabética e alfabética. Cada uma das hipóteses remete a construção da escrita
} 
DOI: $10.12957 /$ e-mosaicos.2020.45091

em ciclos de três $\operatorname{anos}^{6}$, estes estudantes em geral não apresentam distorção série/idade.

De acordo com o site do programa, o PNAIC tem por objetivo:

O Pacto Nacional pela Alfabetização na Idade Certa tem o propósito de apoiar todos os professores que atuam no ciclo de alfabetização, incluindo os que atuam nas turmas multisseriadas e multietapa, a planejarem as aulas e a usarem de modo articulado os materiais e as referências curriculares e pedagógicas ofertados pelo MEC às redes que aderirem ao Pacto Nacional pela Alfabetização na Idade Certa e desenvolverem as ações desse Pacto. (FNDE: 2013)

Dentro deste ambiente formativo um questionamento recorrente entre as professoras alfabetizadoras referia-se à produção de frases pelos alunos durante o ciclo de alfabetização. As questões orbitavam em torno da suposta pobreza das produções em resposta aos exercícios propostos. Tais exercícios comumente introduziam uma palavra/gravura, geralmente um substantivo, a partir do qual o educando deveria redigir suas frases.

As inquietações apresentadas pelas professoras cursistas fomentaram a reflexão tanto sobre a língua quanto sobre prática pedagógica e geraram propostas diferenciadas regidas à luz da análise gramatical e à luz do conceito de letramento.

\section{BREVE ANÁLISE SINTÁTICA E GRAMATICAL DO EXERCÍCIO}

Enquanto formadora do PNAIC procurei gerir os encontros de formação na reflexão sobre prática e na construção de atividades e sequências didáticas que facilitassem aprendizagens para a apropriação da escrita para esses alunos oriundos de classes populares.

Dentro desse contexto de discussões sobre como facilitar aprendizagens, é que a inquietação sobre o conteúdo das frases dos educandos sobressaiu, pois cursistas de diferentes escolas evidenciaram o mesmo tipo de frase produzida independente da hipótese de escrita na qual a criança encontrava-se.

em diferentes "fases", desde a compreensão da escrita como espécie de figura até entendimento da escrita através do uso de letras para escrever e da correspondência fonética.

${ }^{6}$ O sistema de ciclos de alfabetização é uma forma de progressão continuada que passa ser utilizada em maior escala partir de 1996 com a implementação da Lei de Diretrizes e Bases da Educação e em grande escala nas escolas públicas quando da implementação do Ensino Fundamental de nove anos, entre os anos 2004 e 2006. Nesse sistema, o período que compreende o primeiro e o terceiro ano do Ensino Fundamental se torna parte de um processo ininterrupto para que a alfabetização ocorra. Desse modo, ao ingressar no primeiro ano do Ensino Fundamental os estudantes iniciam o processo de alfabetização que deverá se concretizar até o terceiro ano, não havendo retenção entre os anos de escolaridade. Atualmente, há uma discussão sobre a redução do ciclo para o período de dois anos, discussão essa fortemente fundamentada nas orientações específicas da Base Nacional Curricular Comum para esses anos de escolaridade. 
DOI: $10.12957 /$ e-mosaicos.2020.45091

As construções similares à: "A flor é bonita" (artigo+ substantivo + verbo de ligação + adjetivo) repetiam- se nas produções de quase todos os alunos. Alunos em hipótese silábico-alfabética, alfabética e mesmo ortográfica (ou seja, alunos que já refletiam sobre a ortografia das palavras) produziam o mesmo tipo de frase. Pouquíssimos alunos fugiam à regra acima apresentada e a investigação quanto ao porquê destas produções repetidas fez-se necessária.

Observamos, ainda, uma forte tendência à proposição de exercícios baseados em práticas tradicionais, apesar da ideia conceitual do letramento já estar introduzida à maioria das cursistas. Ao aludirmos a práticas tradicionais estamos nos referindo os exercícios de inspiração cartilhesca, dissociados das situações reais de uso da língua escrita, fortemente influenciados por perspectivas de ensino de língua materna que desconsideram o saber que o falante nativo possui de sua língua. Considerando a hipótese de que talvez a problemática da produção de frases estivesse no exercício proposto, sugerimos as professoras aplicação de uma sequência de atividades para observar as características da produção frasal dos estudantes.

De um total de vinte professoras, três se disponibilizaram a aplicar as atividades sugeridas para testarmos a hipótese norteada pela concepção de gramática internalizada. Uma das professoras se propôs a elaborar uma sequência didática atrelada ao conceito de letramento que entremeia o Pacto. Sequência esta a ser vista e analisada nos tópicos que seguem. Preservamos em anonimato o nome das escolas e dos alunos visando garantir a parceria das cursistas para a coleta de dados da amostragem. aplicado:

Vejamos a produção dos alunos, dado o exercício tal como era cotidianamente ESCOLA 1. Exemplo de exercício proposto:

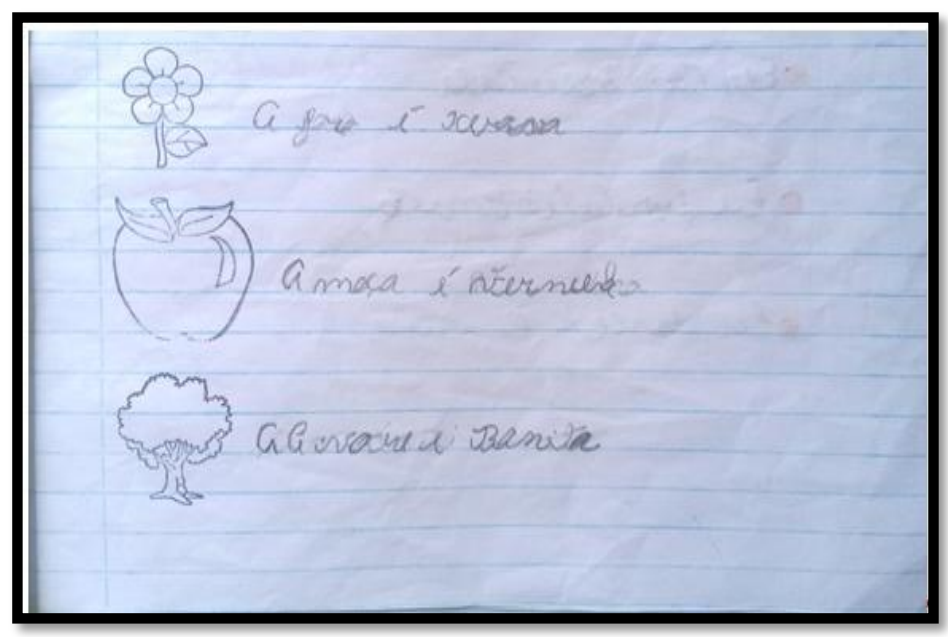


DOI: $10.12957 /$ e-mosaicos.2020.45091

Tabela 1: Produção dos alunos

\begin{tabular}{|l|l|}
\hline Nome dos alunos & Frases produzidas" \\
\hline LANNA & 1. A flor é "xerosa". \\
& 2. A maça é vermelha. \\
\hline KAYKY & 3. A arvore é bonita. \\
\hline KAIO & 1. A flor é bonita. \\
& 2. A maçã é muito gostosa. \\
& 3. A "arvore" da muito fruto. \\
\hline AMANDA & 1. A flor é muito "bunita" \\
& 2. A maça e vermelha \\
& 3. A "arvore" é muito "bunita" \\
\hline LORRAYNE & 1. A flor é "xerosa" \\
& 2. A maçã e "gostoza" \\
& 3. A árvore e linda \\
\hline VITÓRIA & 1. A flor é "bunita" \\
& 2. A "maça" é gostosa \\
& 3. A "arvore" é "bunita" \\
\hline & 1. A flor é bonita \\
& 2. A "maça" e gostosa \\
& 3. A árvore "da" fruto \\
\hline
\end{tabular}

Fonte: Elaborada pela autora.

ESCOLA 2.

Exemplo de exercício proposto:

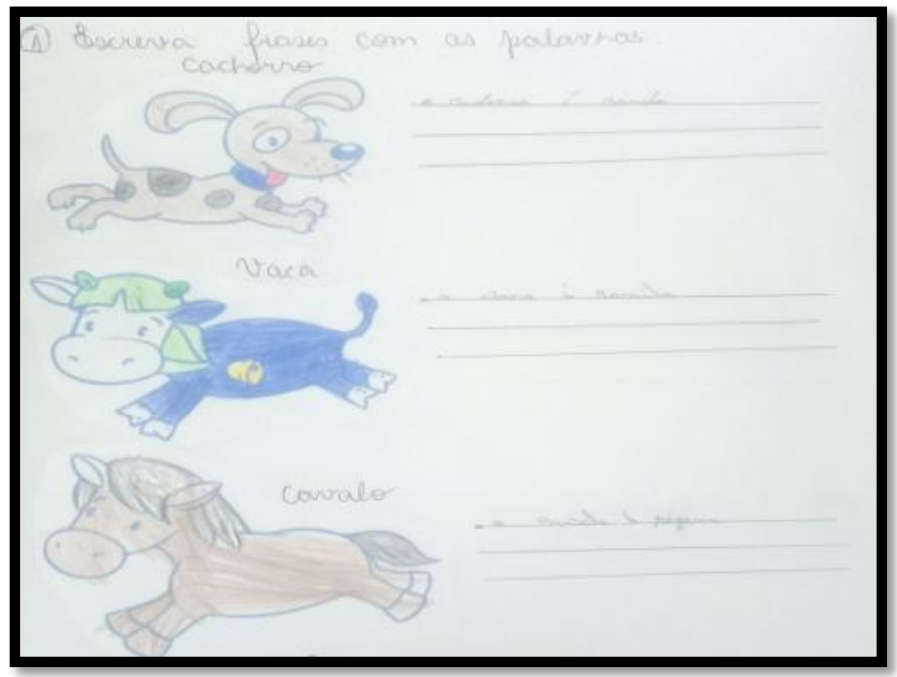

\footnotetext{
${ }^{7}$ Sinalizamos que optamos por analisar as frases apenas de alunos em hipóteses silábico-alfabética e alfabética de escrita. As frases foram transcritas tal qual os alunos escreveram. Ressaltamos que estes alunos ainda estão em processo de alfabetização e, portanto, a escrita ortográfica ainda não está totalmente consolidada. Neste texto não pretendemos centralizar nossas análises e discussões na ortografia das palavras, mas sim na construção frasal dos educandos.
} 
DOI: $10.12957 /$ e-mosaicos.2020.45091

Tabela 2: Produção dos alunos

\begin{tabular}{|l|l|}
\hline Nomes dos alunos & Frases produzidas \\
\hline WESLEY & 1. O cachorro é bonito \\
& 2. A vaca é bonita \\
& 3. O cavalo é pequeno \\
\hline SAMIRA & 1. O cachorro é bonito \\
& 2. A vaca é feia \\
& 3. O cavalo é grande \\
\hline LUCAS & 1. O cachorro é "lido" \\
& 2. A vaca é bonita \\
& 3. O cavalo é do João \\
\hline
\end{tabular}

Fonte: Elaborado pela autora.

ESCOLA 3.

Exemplo de exercício proposto:

Tabela 3: Produção dos alunos

\begin{tabular}{|l|l|}
\hline Nome dos alunos & Frases produzidas \\
\hline THIAGO & 1. O bolo "e" de chocolate \\
& 2. A flor é rosa \\
& 3. A garota é branca \\
\hline LARISSA & 1. O bolo é de chocolate \\
& 2. A flor é vermelha \\
& 3. A garota é feia \\
\hline LUANE & 1.O bolo é de chocolate \\
& 2. A flor é bonita \\
& 3. A garota caiu \\
\hline RODRIGO & 1. O bolo é de morango \\
& 2. A flor é amarela \\
& 3. A garota caiu \\
\hline & O bolo é de chocolate \\
& A flor é rosa \\
& A garota é boa \\
\hline
\end{tabular}

Fonte: Elaborado pela autora 
DOI: $10.12957 /$ e-mosaicos.2020.45091

Observamos nos exercícios realizados pelos alunos de diferentes escolas a repetição de enunciados, constituídos em sua maioria pelo verbo de ligação "ser" conjugado em terceira pessoa do singular, seguido de um adjetivo.

Acreditamos que isto ocorre porque em língua portuguesa as frases que possuem como núcleo, ou palavra mais significativa, um substantivo são precisamente as frases de predicado nominal, produzidas pelos alunos. Ou seja, as frases construídas pelos alunos estão de acordo com seus conhecimentos internalizados quanto à língua materna.

A gramática internalizada, segundo Possenti (2006), refere-se ao "conjunto de regras que o falante domina". Isto é, trata-se de um conhecimento internalizado em língua materna que sugere quais seriam os usos comuns de uma língua nas mais diversas situações comunicativas. Assumindo o aluno como falante nativo, torna-se mais fácil a compreensão das repostas geridas por estes, na situação problema proposta.

É evidente que o educando no ciclo não possui consciência das nomenclaturas utilizadas para classificação das frases, porém não é possível desconsiderar que possui um claro funcionamento da gramaticalidade de sua língua na modalidade oral. E é justamente este vasto conhecimento que ele demonstra em suas construções. Considerar que escrever uma frase como a "A flor é cheirosa." é menos criativa ou demanda menos esforço em sua produção que "Lucas fez um gol." não se justifica gramaticalmente. São predicados diferentes que possuem funções comunicativas diferentes em contextos também diferentes.

As supostas frases "criativas" que as cursistas esperavam seriam nesta perspectiva, frases com verbos transitivos que implicariam uma constituição frasal com objetos diretos, objetos direto-indiretos ou objetos indiretos. Nesse sentido, visualizamos a incoerência na assertiva proposta: solicitamos aos alunos que produzam frases que possuam por núcleo um substantivo, ou seja, frases com predicados nominais, mas esperamos frases com predicados verbais, cujo núcleo ou a palavra mais significativa seria precisamente um verbo, e um verbo transitivo posto que as construções com verbos intransitivos como "A garota caiu." (artigo +substantivo+ verbo) também foram apontadas pelas educadoras como pouco criativas.

No caso dos exercícios propostos desconsidera-se que os alunos já dominam a gramática de sua língua na modalidade oral e, portanto, constroem precisamente o que Ihes é solicitado: uma frase cujo núcleo é o substantivo dando origem a um predicado nominal, constituído de verbo de ligação acrescido de um predicativo do sujeito invariavelmente na maioria dos exercícios.

Outra nota interessante é o uso do artigo nas frases, demonstrando um claro conhecimento da língua materna na construção frasal. Ou seja, o educando ao construir a frase possui o manifesto conhecimento que este tipo de frase em língua portuguesa geralmente inicia-se com um artigo, ou em uma análise sintagmática um determinante. 
DOI: $10.12957 /$ e-mosaicos.2020.45091

Outro dado a ser considerado como elemento que pode justificar a repetição nas produções se deve ao fato de que um objeto/substantivo ao ser sugerido como palavra-tema de uma frase pode gerar um número finito de predicativos coerentes. São poucos os adjetivos não metafóricos que poderão ser atribuídos a uma maçã, a uma flor ou a um cavalo. Ao questionarmos os alunos induzindo-os, dentro desta proposta, a produzirem enunciados diferentes de "A maçã é vermelha." Geramos frustração e até mesmo retrocesso quanto seus pressupostos estabelecidos sobre a gramática internalizada da língua materna.

Pode até mesmo partir deste princípio desconstruído a enorme dificuldade dos estudantes, já no segundo segmento do Ensino Fundamental, compreenderem a diferença entre predicados verbais e nominais e demais conceitos quanto à sintaxe tão utilizados na modalidade oral da língua e tão difíceis de serem visualizados na análise sintática de sua própria língua.

\section{Preconceito linguístico e CONSTRUÇÃo fRASAL}

As intervenções das professoras ao se depararem com este tipo de produção usualmente buscavam relacionar as repetições nos predicados à falta de criatividade e de vocabulário dos educandos ao construírem suas frases. Algumas até julgavam se tratar de apatia ou falta de interesse na realização das atividades. Dificilmente 0 questionamento volta-se a proposta do próprio exercício em relação à palavra escolhida como tema para a produção da frase. E é neste sentido que se evidencia o preconceito linguístico.

Para Marcos Bagno (1999) o preconceito linguístico é gerado dentro de uma lógica de que o falante nativo do português brasileiro, sobretudo os que não se utilizam da norma culta, ou padrão, não possuem domínio de sua língua materna. Essa lógica, incoerente com os estudos em linguística também apresentados no livro "Preconceito linguístico. O que é, como se faz," é referendada por mitos que se utilizam da gramática normativa para propagar as falsas afirmativas de que "brasileiro não sabe português" ou ainda que o "português correto é o falado em Portugal".

Essas afirmativas, dentre outras que ratificam o preconceito linguístico se apoiam na perspectiva excludente de cunho evidentemente social, sinalizando a estratificação social evidenciadas nos discursos produzidos a partir das variações linguísticas diastráticas.

As concepções nas quais operam a lógica do preconceito linguístico estão enraizadas em nossas práticas pedagógicas de tal forma que criticamos a construção frasal dos alunos desconsiderando seu saber de falante nativo. $O$ preconceito embaça nosso olhar quanto à produção dos educandos impossibilitando o pensar/refletir sobre as deficiências nos exercícios propostos culpabilizando os educandos, sobretudo quando tratamos de alunos oriundos de classes populares, quanto às repetições nas frases acima apresentadas. Para a desconstrução deste preconceito, Bagno aponta 10 cisões para um ensino de língua menos preconceituoso, entre as quais sinalizamos 2: 
DOI: $10.12957 /$ e-mosaicos.2020.45091

1. Conscientizar-se de que todo falante nativo de uma língua é um competente usuário desta língua. Entre os 3 e 4 anos de idade, uma criança já domina integralmente a gramática de sua língua.

(...)

10. Ensinar bem é ensinar para o bem. Ensinar para o bem significa respeitar o conhecimento intuitivo do aluno, valorizar o que ele já sabe do mundo, da vida, reconhecer na língua que ele fala sua própria identidade como ser humano.(...)

Ainda segundo Bagno:

Todo falante nativo de uma língua sabe essa língua. Saber uma língua, no sentido científico do verbo saber, significa conhecer intuitivamente e empregar com naturalidade as regras básicas de funcionamento dela. (BAGNO: 1999 p.35)

Segundo Cagliari "Quando se diz que a criança já é um falante nativo de uma língua, significa que ela dispõe de um vocabulário e de regras gramaticais" (CAGLIARI: 2009 p.15), afirmação referendada por diversos autores e linguísticas que concordam que pela idade de 3 a 5 anos a criança já domina a língua materna na modalidade oral. (HOCKET: 1995; SILVA: 2004; BAGNO: 1999).

Desse modo, foi necessário despir-se deste preconceito para repensar a prática pedagógica, esta sim, repetitiva e utilizada há vários anos nas instituições escolares.

A fim de testar a hipótese de que a problemática girava em torno da atividade em si mesma e não na falta de vocabulário e motivação das crianças, sugerimos as cursistas uma mudança no exercício. Incumbidas de proporem a mesma atividade, porém com diferentes verbos como palavra-tema, as professoras-cursistas notaram sensível diferença quanto à produção dos enunciados. verbos:

Vejamos a produção dos mesmos alunos dada à apresentação da atividade com ESCOLA 1.

Exemplo de exercício:

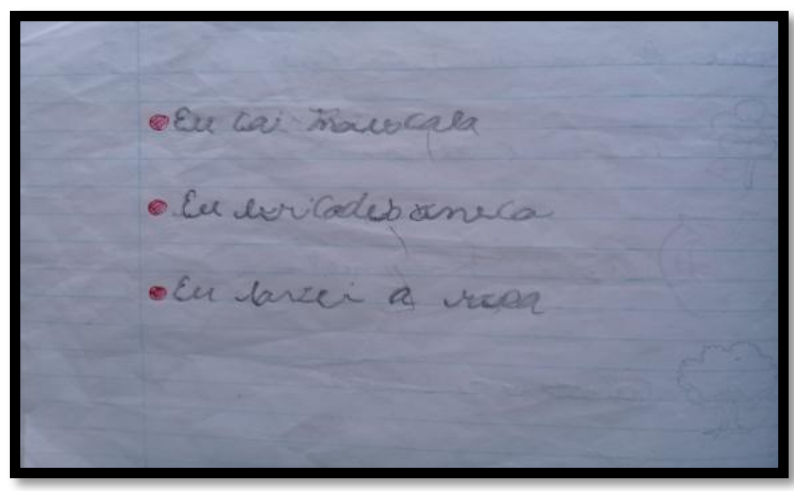


DOI: $10.12957 /$ e-mosaicos.2020.45091

Tabela 5: Produção dos alunos

\begin{tabular}{|c|c|}
\hline Nomes dos alunos & Frases produzidas \\
\hline LANNA & $\begin{array}{l}\text { 1.Eu caí "naescola" } \\
\text { 2. Eu "brico" de boneca } \\
\text { 3. Eu lavei a "ropa" }\end{array}$ \\
\hline KAYKY & $\begin{array}{l}\text { 1. A "pedracaiu" } \\
\text { 2. "Hoge" brinquei muito } \\
\text { 3. 'Minhamae" lava muita "ropa" }\end{array}$ \\
\hline KAIO & $\begin{array}{l}\text { 1. Eu caí da árvore } \\
\text { 2. Eu brinquei "oi"(hoje) } \\
\text { 3. Eu lavei o carro }\end{array}$ \\
\hline AMANDA & $\begin{array}{l}\text { 1. A pedra caiu } \\
\text { 2. Eu brinco com meus amigos } \\
\text { 3. O meu pai "lavol"o carro }\end{array}$ \\
\hline LORRAYNE & $\begin{array}{l}\text { 1. O meu primo caiu } \\
\text { 2. Eu brinquei de "piquepega" com a } \\
\text { minha prima } \\
\text { 3. Eu lavei roupa }\end{array}$ \\
\hline VITÓRIA & $\begin{array}{l}\text { 1. Kaio caiu do "moro" } \\
\text { 2.. Meu pai "brincol" hoje } \\
\text { 3. Minha mãe "lavol" a roupa }\end{array}$ \\
\hline
\end{tabular}

Fonte: Elaborado pela autora.

ESCOLA 2.

Exemplo de exercício proposto: 
DOI: $10.12957 /$ e-mosaicos.2020.45091

Tabela 6: Produção dos alunos

\begin{tabular}{|c|c|}
\hline Nome dos alunos & Frases produzidas \\
\hline WESLEY & $\begin{array}{l}\text { 1. Felipe jogou bola } \\
\text { 2. O Cauã deu para o gol } \\
\text { 3. O cachorro comeu o osso }\end{array}$ \\
\hline SAMIRA & $\begin{array}{l}\text { 1. O menino jogou a bola } \\
\text { 2. A menina deu a bola } \\
\text { 3. O cachorro comeu o "oso" }\end{array}$ \\
\hline LUCAS & $\begin{array}{l}\text { 1. O menino jogou bola } \\
\text { 2. Tiago deu bala para Bia } \\
\text { 3. O Marcos comeu comida" }\end{array}$ \\
\hline
\end{tabular}

Fonte: Elaborado pela autora

ESCOLA 3.

Exemplo de exercício proposto:

Tabela 7: Produção dos alunos

\begin{tabular}{|c|c|}
\hline Nome dos alunos & Frases produzidas \\
\hline THIAGO & $\begin{array}{l}\text { 1. O garoto comeu "melansia" } \\
\text { 2. A Caroline pulou na "pisina" } \\
\text { 3. A Júlia jogou "videoame"(vídeo game) }\end{array}$ \\
\hline LARISSA & $\begin{array}{l}\text { 1. Ele comeu morango } \\
\text { 2. Ela pula na "picina" } \\
\text { 3. Ele jogou bola }\end{array}$ \\
\hline LUANE & $\begin{array}{l}\text { 1. Lucas comeu abacaxi } \\
\text { 2. Maria foi no "pula pula" } \\
\text { 3. O jogo do João e Lucas acabou }\end{array}$ \\
\hline
\end{tabular}


DOI: $10.12957 /$ e-mosaicos.2020.45091

\begin{tabular}{|l|l|}
\hline RICARDO & $\begin{array}{l}\text { 1. O menino comeu uva } \\
\text { 2. O menino pula no "pula pula" } \\
\text { RODRIGO }\end{array}$ \\
\hline $\begin{array}{l}\text { 3. O menino jogou a bola longe } \\
\text { 1. O gato comeu sardinha }\end{array}$ \\
$\begin{array}{l}\text { 2. O menino pulou na água } \\
\text { 3. O menino jogou videogame }\end{array}$ \\
\hline
\end{tabular}

Fonte: Elaborado pela autora

Há uma mudança significativa nas frases dos educandos. Observamos uma produção mais variada ao apresentarmos o verbo enquanto palavra-tema. Acreditamos que isto ocorre, pois, dentro de uma infinidade de possibilidades para a escolha de sujeitos e objetos, as repetições tornam-se menos comuns.

Assim, concluímos que as supostas frases criativas na expectativa das cursistas, tratam-se na verdade de frases construídas com verbos transitivos, formadas por predicados verbais. Ou seja, orações que possuam como núcleo de maior representatividade um verbo. Torna-se, então, evidente a incoerência de esperar dos alunos uma frase com predicado verbal apresentando como núcleo para esta produção um substantivo.

\section{LETRAMENTOS E CONSTRUÇÃO FRASAL}

A alternativa para construção de frases no ciclo de alfabetização insere-se na crítica à proposição deste tipo de atividade descontextualizada e mecânica alinhada a uma proposta de alfabetização pautada sob os pilares do letramento.

Os estudos mais atuais quanto ao letramento no Brasil compreendem hoje que o termo é plural: existem letramentos (ROJO: 2009). Nesse sentido há uma ampliação do conceito de literacy (em tradução literal do inglês) devido à dificuldade do termo, em língua portuguesa, de abranger todos os significados do que seria ler e escrever.

Atualmente há certo consenso de que o termo "alfabetização" refere-se "a ação de alfabetizar, de ensinar a ler e a escrever, que leva o aprendiz a conhecer o alfabeto, a mecânica da escrita/leitura, a se tornar alfabetizado" (ROJO: 2009), ou ainda como resume Magda Soares um "processo de aquisição do código escrito, das habilidades de leitura e escrita" (SOARES: 2011) e, que o termo letramento se relaciona às práticas sociais de uso da leitura e da escrita. Assim o letramento é o:

estado ou condição de quem não só sabe ler e escrever MAS exerce as práticas sociais de leitura e de escrita que circulam na sociedade em que vive, conjugando-as com práticas as sociais de tradição oral. (Soares, 1999 p.3) [grifos da autora] 
DOI: $10.12957 / \mathrm{e}-\mathrm{mosaicos} .2020 .45091$

Ainda segundo Soares:

É verdade que, de certa forma, a aprendizagem da língua materna, quer escrita quer oral, é um processo permanente, nunca interrompido. Entretanto, é preciso diferenciar um processo de aquisição da língua (oral e escrita) de um processo de desenvolvimento da língua (oral e escrita); este último é que, sem dúvida, nunca é interrompido. (SOARES: 2011 p. 15)

Isto significa dizer que sem desconsiderar os eventos e práticas de letramento a que os alunos estão constantemente submetidos, a escola deverá favorecer o desenvolvimento das habilidades em leitura e escrita dos educandos.

Configuramos no ambiente do PNAIC, a compreensão do letramento como "práticas sociais de leitura e escrita" (SOARES: 2011). Desse modo, uma das cursistas encarregou-se de aplicar uma proposta em letramento para produção de frases no ambiente do pacto. A sequência didática proposta pela professora-cursista possuía por objetivo utilizar-se da escrita para expressar opiniões e pensamentos a respeito de leituras realizadas em sala.

Segundo Pessoa (2014), o termo Sequência didática se refere a um conjunto de atividades articuladas e planejadas com a intenção de atingir determinado objetivo didático. A autora ainda comenta que:

A sequência didática é uma forma de organização do trabalho pedagógico que permite antecipar o que será enfocado em um espaço de tempo que é variável em função do que os alunos precisam aprender, da mediação e do constante monitoramento que o professor faz para acompanhar os alunos, por meio de atividades de avaliação durante e ao final da sequência didática. (PESSOA: 2014 p.301-302)

A sequência didática se estabeleceu em quatro etapas:

Etapa 1: Leitura do "O peixe e a passarinha" de Blandina Franco e José Carlos Lollo (Companhia das Letrinhas; 2012). Nessa etapa, a professora realizou a leitura do livro para as crianças. Este momento, conhecido como "leitura deleite" é uma das propostas do PNAIC para as aulas de língua portuguesa, cujo um dos objetivos é promover o prazer de ler ao conhecer histórias diferentes e trabalhar a competência leitora a partir dos momentos de leitura. O próprio livro escolhido faz parte do acervo de livros enviado às escolas para uso das turmas em processo de alfabetização.

Etapa 2: Roda de conversa sobre a leitura. Após a leitura a professora sentou-se com os alunos para conversar sobre o texto, as ilustrações e as sequências de narrativas apresentadas no livro. Os momentos de roda de conversa visavam 
DOI: $10.12957 /$ e-mosaicos.2020.45091

trabalhar elementos importantes para expressão na oralidade. Elementos que devem ser ensinados como o respeito aos turnos de fala, tom adequado para a roda de conversa, organização dos pensamentos a serem expostos em seus momentos de fala, dentre outros que compõem a oralidade e que podem ser trabalhados em sala de aula.

Etapa 3: Produção Textual. Nessa fase, solicitou-se aos alunos que produzissem frases que explicassem o que cada um entendeu a respeito dos personagens e representassem através da escrita suas impressões sobre o texto. Alguns alunos inclusive nomearam os personagens no momento da escrita.

Etapa 4: Ilustração das produções textuais propostas. Finalizando a sequência os alunos ilustraram as frases que produziram a fim de socializar suas produções para a professora e colegas da turma.

Analisemos a produção dos alunos:

ESCOLA 4.

Exemplo de atividade proposta:

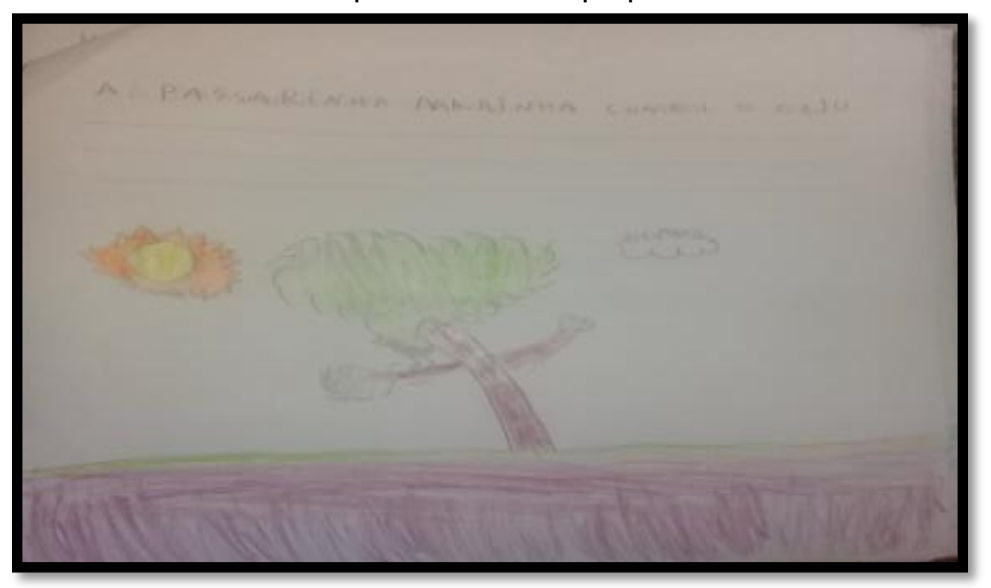

Tabela 8: Produção dos alunos

\begin{tabular}{|l|l|}
\hline Nomes dos alunos & Frases produzidas \\
\hline ENZO & O peixe e a passarinha se apaixonaram \\
\hline RICARDO & A passarinha olhava o mar \\
\hline RICARDO TEXTO 2 & A passarinha marinha comeu o caju \\
\hline IZABEL & Maria comeu limão \\
\hline MARIA & Eu gosto da passarinha \\
\hline MARIA TEXTO 2 & Passarinha Dudinha olhou a água \\
\hline SOLIANE & $\begin{array}{l}\text { A passarinha é muito bonita e é } \\
\text { apaixonada pelo peixe }\end{array}$ \\
\hline
\end{tabular}


DOI: $10.12957 / \mathrm{e}-\mathrm{mosaicos} .2020 .45091$

\begin{tabular}{|l|l|}
\hline LORENA & O passarinho olha o mar \\
\hline FABIANO & A passarinha Flor comeu a minhoca \\
\hline KEVEN & $\begin{array}{l}\text { Eu gosto de peixe e o peixe gosta da } \\
\text { passarinha }\end{array}$ \\
\hline KEVEN TEXTO 2 & Dentuço olhou pro céu \\
\hline MARINA & O peixe é bonito \\
\hline MARINA TEXTO 2 & "Peixe João olhou "minoca"( minhoca) \\
\hline THIAGO & $\begin{array}{l}\text { Eu gosto de passarinha } \\
\text { A passarinha "Monica" comeu "minoca } \\
\text { ULYSSES }\end{array}$ \\
\hline LEILA & $\begin{array}{l}\text { O pexe" nada } \\
\text { peixe }\end{array}$ \\
\hline LARISSA & peixe "e" "bunidinho" e olhou o \\
\hline
\end{tabular}

Fonte: Elaborado pela autora

As diferenças apresentam-se de forma significativa quanto à produção frasal neste contexto. Primeiramente é preciso destacar que o texto não foi utilizado como um pretexto para produção das frases. Dentro da rotina diária há sempre um período dedicado à leitura dos livros paradidáticos enviados a escola pelo programa. Este momento é realizado diariamente, normalmente iniciando ou finalizando as aulas. 0 que a professora-cursista solicitou aos alunos foi à escrita dessas impressões sobre o texto que comumente eram realizadas somente na oralidade.

Outro ponto de extrema relevância é a funcionalidade da produção. Tal como nos sinaliza Cagliari "NÃO BASTA SABER ESCREVER PARA ESCREVER. É preciso ter uma motivação para isto". (CAGLIARI: 2009) [grifos do autor]. Diferentemente das propostas anteriores cujo único objetivo seria verificar a escrita dos educandos a partir de uma atividade mecanizada de construção de frases, ressaltamos que as frases produzidas nesta sequência didática possuem uma função social de interação comunicativa: expor as impressões dos alunos sobre o texto para os colegas de classe e para professora. A ideia de sugerir que ilustrassem as frases também possui significado posto que facilita a compreensão do que os alunos gostariam de expressar aos demais educandos. Estes pontos tornaram a escrita significativa:

Entendemos por escrita significativa, as escritas propostas com objetivos e interlocutores definidos, inseridas em práticas sociais articuladas aos gêneros textuais que circulam atualmente em nossa sociedade. (ARCENIO; 2017)

Destacamos nessas atividades um esforço dos alunos para expressarem suas impressões da história, contarem os trechos que acharam mais interessantes e nomear personagens a partir de suas reflexões sobre o texto. Também se estabelecem reais 
DOI: $10.12957 /$ e-mosaicos.2020.45091

níveis de complexidade gramatical na escrita das frases à medida que surgem orações coordenadas observadas na produção dos alunos Larissa, Keven e Soliane.

E apesar da temática ser a mesma para todas as frases, a diversidade na produção das sentenças é inegável e a repetição de predicados é praticamente nula.

\section{CONCLUSÃo}

Assim, este artigo procurou investigar a produção de frases no ciclo de alfabetização a partir da análise das atividades comumente propostas nesta fase do Ensino Fundamental. Ressaltamos que a partir do comprometimento e inquietações das professoras-cursistas foi possível pesquisar meios de gerir aprendizagens de forma mais efetiva aos educandos.

$\mathrm{Na}$ análise das produções de diferentes escolas evidencia-se que o preconceito linguístico, ainda que involuntariamente, manifesta-se quanto à produção frasal dos alunos, posto que no ambiente de formação os questionamentos orbitaram sempre em torno da suposta "pobreza criativa" e falta de motivação por parte dos discentes em realizar as atividades. A partir da desconstrução destes conceitos arraigados a prática pedagógica foi possível visualizar a problemática em torno das produções. Problemática esta, intimamente ligada à proposta do exercício fundamentado em práticas tradicionais dissociadas dos contextos geridos em letramento e que desconsidera as capacidades e conhecimentos prévios que o estudante possui enquanto falante nativo.

Compreendemos ao final desta análise que os estudantes, em verdade, produziram frases de acordo com o que lhes fora solicitado e de acordo com o contexto de produção que lhes era oferecido.

Portanto, ratificamos a necessidade de uma alfabetização pautada em práticas sociais de leitura e escrita, a fim de que sejam produzidos textos de maior significado de forma que a produção de frases no ciclo de alfabetização seja facilitadora da ampliação das competências leitora e escritora e auxilie na consolidação da apropriação da leitura e da escrita em língua materna.

\section{REFERÊNCIAS}

BAGNO, M. Preconceito linguístico o que é, como se faz. São Paulo: Edições Loyola, 1999.

CAGLIARI, L. C. Alfabetização e Linguística _ 11.ed. São Paulo: Scipione: 2009. (Coleção Pensamento e ação na sala de aula).

HOCKETT C. A course in Modern Linguistics. In: LUFT, Celso Pedro. Língua e Liberdade. Porto Alegre, LP\&M, 1985. 
DOI: $10.12957 /$ e-mosaicos.2020.45091

PESSOA, A. C. R. G. Sequência Didática. In: FRADE, I. C. A.S.; VAL, M. da G. C. G.; BREGUNCI, M. das G. C. Glossário Ceale de termos de Alfabetização, leitura e escrita para educadores. Belo Horizonte, CEALE: 2014 p.301-302.

POSSENTI, S. Sobre o ensino de português na escola. In GERALDI, J.W. (org). 0 texto na sala de aula. São Paulo, Ática: 2006

ROJO, R. in: ROJO, R.; ALMEIDA, E. M. (Orgs.). Multiletramentos na escola. São Paulo: Parábola Editorial, 2012.

Letramentos múltiplos, escola e inclusão social. São Paulo: Parábola Editorial: 2009

SILVA, R.V.M. "O português são dois..." Novas fronteiras, velhos problemas. São Paulo, Parábola Editorial, 2004.

SOARES, M. Letramento: um tema em três gêneros. São Paulo: Autêntica 1999. Alfabetização e Letramento. São Paulo, Contexto: 2011.

Sites Consultados:

ARCENIO, C.R. C. A influência de interculturalidade funcional na apropriação da leitura e da escrita. Anais do evento IX Seminário Internacional As Redes Educativas e as Tecnologias. UERJ: 2017. Disponível em:

http://www.seminarioredes.com.br/ixredes/adm/trabalhos/diagramados/TR867.pdf Acesso em 24/01/2018.

FNDE. Pacto Nacional Pela Alfabetização na Idade Certa. Disponível em www.fnde.gov.br/.../6433-pacto-nacional-pela-alfabetização-da-idade-certa---pnaic

Glossário CEALE. Termos de Alfabetização, Leitura e Escrita para educadores_ ISBN: 978858007078. Disponível em: http://ceale.fae.ufmg.br/app/webroot/glossarioceale/. Acesso em 24/10/2016.

Recebido em 06 de setembro de 2019 Aceito em 22 de novembro de 2019

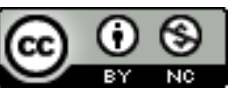

A e-Mosaicos Revista Multidisciplinar de Ensino, Pesquisa, Extensão e Cultura do Instituto de Aplicação Fernando Rodrigues da Silveira (CAp-UERJ) está licenciada com uma Licença Creative Commons - Atribuição-NãoComercial 4.0 Internacional.

Os direitos autorais de todos os trabalhos publicados na revista pertencem ao(s) seu(s) autor(es) e coautor(es), com o direito de primeira publicação cedido à e-Mosaicos.

Os artigos publicados são de acesso público, de uso gratuito, com atribuição de autoria obrigatória, para aplicações de finalidade educacional e não-comercial, de acordo com o modelo de licenciamento Creative Commons adotado pela revista. 